\title{
Kernos
}

Revue internationale et pluridisciplinaire de religion grecque antique

30 | 2017

Varia

\section{Dieux des Grecs, dieux des Romains. Panthéons en dialogue à travers l'histoire et l'historiographie}

\section{Yann Berthelet}

\section{(2) OpenEdition \\ Journals}

Édition électronique

URL : http://journals.openedition.org/kernos/2518

DOI : 10.4000/kernos.2518

ISSN : 2034-7871

Éditeur

Centre international d'étude de la religion grecque antique

Édition imprimée

Date de publication : 1 octobre 2017

Pagination : 329-332

ISSN : 0776-3824

Référence électronique

Yann Berthelet, « Dieux des Grecs, dieux des Romains. Panthéons en dialogue à travers l'histoire et I'historiographie », Kernos [En ligne], 30 | 2017, mis en ligne le 01 octobre 2017, consulté le 24 septembre 2020. URL : http://journals.openedition.org/kernos/2518 ; DOI : https://doi.org/10.4000/ kernos. 2518

Ce document a été généré automatiquement le 24 septembre 2020 


\title{
Dieux des Grecs, dieux des Romains. Panthéons en dialogue à travers l'histoire et l'historiographie
}

\author{
Yann Berthelet
}

\section{RÉFÉRENCE}

Corinne BONNET, Vinciane PIRENNE-DELFoRGE, Gabriella PIRONTI (dir.), Dieux des Grecs, dieux des Romains. Panthéons en dialogue à travers l'histoire et l'historiographie, Bruxelles-Rome, Institut Historique Belge de Rome, 2016. 1 vol. $19 \times 25,5$ cm, 249 p. ISBN : 978-90-74461$81-8$.

1 Ainsi que le précisent dans leur introduction les éditrices scientifiques, l'enjeu de cet ouvrage collectif est de confronter, dans le cadre de dialogues à géométrie variable, les dieux « grecs » des Romains et les dieux « romains » des Grecs aux façons romaines de construire la Grèce, comme aux façons grecques de reconfigurer du romain. - Dans un remarquable chapitre liminaire, où le célèbre passage de Tacite sur l'interpretatio Romana (Germanie, 43,4) est passé au crible de l'analyse, Maurizio BETTINI met en garde le lecteur contre un emploi erroné de la catégorie d'interpretatio comme une simple «traduction » des noms des dieux, supposés les mêmes partout: un tel usage abusif non seulement obscurcirait la dimension expérimentale de toute interpretatio - qui, parfois guidée par l'iconographie, repose toujours sur des analogies et des conjectures -, mais empêcherait également de l'appréhender dans son contexte culturel propre. Interpréter (interpretari) les dieux des autres, faire sur eux des conjectures (conicere), les

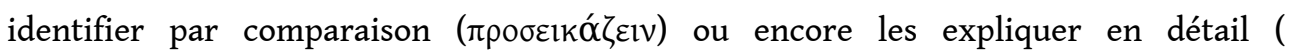
$\dot{\varepsilon} \xi \eta \rho \mu \varepsilon v \varepsilon v ́ \varepsilon ı v)$, constituent des «actes de médiation » qui relèvent tous de la sphère du savoir ('̇ंí $\sigma \tau \alpha \sigma \theta \alpha 1$, nosse ou scire) et procèdent d'une "reconnaissance" des dieux étrangers par référence aux dieux que l'on connaît déjà. - John scHEID aborde le cas des divinités grecques «inventées" par les autorités romaines à l'occasion des Jeux 
séculaires de 17 av. J.-C., célébrés selon la coutume grecque : plutôt que de transcrire Gaia par Tellus ou Cérès ou de s'adresser aux Parques et aux Fata, dont les cultes sont bien attestés à Rome, les organisateurs des Jeux ont préféré les transcriptions érudites Terra mater, Moerae et Ilithyies. Une telle démarche était évidemment consciente, comme le prouve le Carmen saeculare d'Horace qui mentionne Tellus, Cérès et les Parques, et qui commente "à la romaine" le nom d'Ilithyie. - Nicole BeLAYCHE lève le voile sur l'appellation latine courante de la mère des dieux, Mater Magna, qui n'est pas

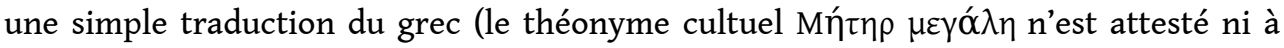
Pessinonte ni même en Anatolie, Érythrées exceptée), mais une construction romaine par verbalisation et explicitation d'une qualité intrinsèque à cette divinité : la grandeur qui accompagne la primauté - grandeur qui présageait, en l'occurrence, le futur imperium universel de Rome. - À partir de trois dédicaces bilingues de Délos ( $\mathrm{II}^{\mathrm{e}} \mathrm{s}$. av. J.C.) et de Beyrouth (II $\mathrm{e}$. ap. J.-C.) et d'une dédicace grecque de Cos (époque impériale), Stéphanie PAUL montre que la mise en relation d'épiclèses grecques et latines procède moins d'un véritable dialogue entre deux panthéons que d'une affirmation identitaire de la part des dédicants (dans les dédicaces bilingues étudiées) ou d'une volonté d'honorer l'empereur (dans l'inscription de cos) par l'adjonction à Zeus de l'épiclèse « romaine » Kapetolios, à côté de son épiclèse topographique locale (Alseios). - Eftychia STAVRIANOPOULOU met en exergue la double capacité divine associée à l'épiclèse epekoos, non seulement la capacité d'écoute, mais aussi celle d'exaucer les prières des dévots. Tirant sans doute son origine d'une iconographie et de pratiques religieuses égyptiennes, elle se développa à l'époque ptolémaïque, dans le cadre d'une idéologie royale qui mettait l'accent sur l'accessibilité du souverain. - Stefano CANEVA rend compte des dynamiques idéologiques et politiques à l'œuvre dans l'interaction entre Dionysos et Liber aux deux derniers siècles de la République. La répression des Bacchanales (186 av. J.-C.), bien que particulièrement brutale, participa en réalité d'une tendance répandue dans le monde hellénistique à réaffirmer, face à la multiplication d'associations de culte non officielles, le rôle des institutions publiques dans la vie religieuse des communautés. L'inscription de Tiriolo - et non pas de «Triolo » (p. 102) - prouve qu'il s'agissait moins d'extirper les cultes bachiques d'Italie que de les soumettre à un contrôle plus étroit. L'épisode d'Alexandrie (140/139av. J.-C.), lors duquel les représentants romains n'éprouvèrent que dégoût face à la truphè d'un Ptolémée VIII costumé en nouveau Dionysos - loin du Dionysos «apollinisé » des Attalides - procéda du même rejet idéologique d'un modèle extérieur perçu comme dangereux. Toute forme de dionysisme ne fut cependant pas rejetée, comme le prouve l'exploitation idéologique du dieu et de son cortège par les grands imperatores de la fin de la République (de Marius à Antoine), dans le cadre d'une conception charismatique et épiphanique du pouvoir personnel, inspirée de la tradition hellénistique. Même sous Auguste, le Liber agricole italique fut hybridé avec un Dionysos passé au filtre de l'idéologie archaïsante du principat. - Francesco MASSA souligne que l'interpretatio des noms divins permettait aux intellectuels grecs et romains non seulement de réfléchir sur l'unité du monde divin, mais aussi de présenter le monde des hommes sous l'angle d'une unité culturelle et cultuelle. Ces processus d'équivalence entre les noms des dieux s'intensifièrent à l'époque impériale, comme l'illustre l'épigramme d'Ausone, qui déroule, avec de légères variantes entre les versions latine et grecque, toutes les dénominations de Dionysos. Le cas de Liber Pater, dont l'identité ne résultait pas de la seule tradition dionysiaque et dont les sphères d'influence différaient en partie de celles du dieu grec, révèle cependant que, malgré la tendance de la koinè dionysiaque, 
avant tout littéraire et iconographique, à gommer les spécificités du dieu romain, les pratiques rituelles restèrent imperméables aux interpretationes et continuèrent à se référer à la seule tradition romaine (présence de Libera aux côtés de Liber). - Valérie HUET met au jour le bricolage d'éléments grecs archaïsants ou classicisants par lequel les Romains construisirent un Mars éclectique - et en cela proprement romain -, dont les images jouent sur la ressemblance et l'écart entre le dieu et l'imperator ou le sacrifiant. - L'étude que Colette JOURDAIN-ANNEQUIN consacre à Héraclès/Hercule dans les Alpes occidentales montre comment son association au dieu local Graius par l'adjonction de l'épiclèse du même nom - le choix de l'A. de parler alors de "syncrétisme» (p.165) est étonnant - participa à la résolution des contradictions ethniques en contexte colonial. Héraclès-Hercule, dont la figure était indissociable du mythe grec de sa geste occidentale et de son franchissement pionnier des sommets alpins, put ainsi absorber les forces vives du dieu indigène et assurer la protection des voyageurs dans l'ascension et le passage des cols - quitte à renoncer, par cette interpretatio, à certaines des fonctions qu'il occupait ailleurs. - Se penchant sur Eleos et Clementia, divinités grecque et romaine personnifiant toutes deux la Pitié - dans le cadre, cependant, d'écheveaux de relations fort différents -, Carmine PISANo met en relief la nécessité d'être attentif à la capacité des Grecs, tel Pausanias, à « indigéniser » (Marshall Sahlins) les dieux et les cultes du nouveau maître romain. - Alessandro SAGGIORO propose plusieurs pistes pour tenter d' éclairer le mystère persistant de Vacuna, déesse sabine intégréeau panthéon romain : son individualitése serait obscurcie au profit de la sphère religieuse deVictoria, plus puissante; un substrat religieux sabin aurait conservé à Vacuna des spécificités la rendant irréductible, en dépit de certaines analogies, à Diane, Minerve, Vénus, Cérès, Bellone ou Victoria ;Vacuna aurait gardé

les traces du processus complexe de formation des peuples sabins, avec une possible empreinte grecque - - Françoise VAN HAEPEREN met en évidence la manière dont Cicéron parvient à présenter les divinités des cités grecques et siciliennes victimes de Verrès comme des dieux fort proches des Romains, en leur appliquant le plus souvent un nom romain, en soulignant le caractère universel de l'Apollon de Délos ou de la Cérès d'Henna, en rappelant la protection que des généraux romains leur ont accordée ou encore en insistant sur l'adoption publique, par les Romains, des sacra Graeca de Cérès. Si le but de Cicéron était bien entendu d'alourdir les charges pesant sur l'accusé, une telle stratégie oratoire ne pouvait fonctionner que si ce type d'arguments faisait écho à des sentiments partagés par les auditeurs et à des habitudes déjà bien ancrées à Rome. Les cas de recusatio par des empereurs d'honneurs divins jugés excessifs, étudiés par Emmanuelle Rosso, se limitèrent aux isotheoi timai risquant d'avoir un impact au-delà de la cité d'origine et d'atteindre Rome. Ils doivent être interprétés selon une équation à trois composantes : évaluation des honneurs précédents, nature des honneurs associés et contexte historico-politique du décret. Partie prenante du système de "pétitionréponse" caractéristique du principat, la dialectique entre honneurs refusés et honneurs acceptés contribuait à dessiner les contours de la figure du prince et révèle à la fois la vitalité de la culture religieuse civique et l'importance de la hiérarchie des majestates au sein de la domus Augusta. - Philippe BORGEAUD trouve dans son Commentaire à Osée (I, 14) la clé de l'interpretatio romana de la Mère des dieux par Jérôme: la justification que ce dernier y donne de sa traduction du féminin hébreu qadeshot (Osée, IV, 14) par le masculin latin effeminati marque non seulement un souci d'elegantia qui 
suppose une adaptation à l'usage actuel de la langue (consuetudo), mais révèle surtout, par l'assimilation qu'elle suppose entre les Galles de la Mère des dieux et les prostituées consacrées à Beelphégor (qu'il assimile à Priape), les fantasmes du traducteur, pour qui la «Mère non pas des dieux mais des démons " est à la castration ce que Priape est à l'ithyphallisme. - Dans une conclusion qui rend justice aussi bien à la richesse de chaque contribution qu'à la cohérence globale de l'enquête collective, Sylvia ESTIENNE et Yves LAFOND rappellent à juste titre que l'interpretatio ne doit pas être réduite à un simple jeu culturel: s'inscrivant souvent dans des stratégies de communication spécifiques, elle visait avant tout à l'efficacité de la dénomination des dieux. Appuyé sur des cas d'étude finement analysés, cet excellent ouvrage contribue de manière significative à rendre aux processus complexes d'interpretatio en contexte polythéiste toute leur épaisseur historique.

\section{AUTEURS}

YANN BERTHELET

Université de Liège 